\title{
The impact of a new hepatopancreatobiliary surgery program on the management of pancreatic cancer at Health Sciences North
}

\author{
Luke Hartford, MD, DVM \\ Véronique Doucet, MD \\ Julie Ramkumar, MD \\ Ken Leslie, MD, MHPE \\ Jeffrey Shum, MD \\ Kengo Asai, MD, PhD
}

This work was presented at the Canadian Surgery Forum 2017, Victoria (BC).

Accepted Jan. 9, 2019; Published online June 1, 2019

\author{
Correspondence to: \\ L. Hartford \\ Department of General Surgery \\ London Health Sciences Centre \\ 800 Commissioners Road East \\ Room E2-213, Zone E \\ London ON N6A 5A5 \\ luke.hartford@Ihsc.on.ca
}

DOI: $10.1503 /$ cjs.016517

\begin{abstract}
Background: Centralization of specialist services to urban centres presents a challenge to patients living in rural communities. The hepatopancreatobiliary surgery (HPB) program at Health Sciences North (HSN) is the tenth and newest HPB centre by Cancer Care Ontario and presents a unique opportunity to evaluate the barriers to delivering HPB cancer care to patients in northern Ontario.

Methods: We retrospectively reviewed the cases of patients referred to the Northeastern Ontario Cancer Centre and HSN with a pancreatic cancer diagnosis between 2009 and 2015. July 2013 marked the inception of the HPB surgical program. Our primary outcome was time to HPB surgical consultation. Secondary outcomes included distance of travel and time to curative intent operation.
\end{abstract}

Results: Our population consisted of 207 patients ( 98 pre-HPB v. 109 post-HPB). Median time to consultation with an HPB surgeon was decreased in the post-HPB group (43 v. $11 \mathrm{~d}, p<0.001)$. An increased proportion of patients with pancreatic malignancies in the post-HPB group received HPB surgical consultations $(34 \% \mathrm{v}$. $74 \%, p<0.001)$, with decreased median distance travelled to surgical consultation (411 v. $79 \mathrm{~km}, p<0.001)$. Time to curative intent operation or medical oncology consultation did not significantly increase.

Conclusion: A new HPB program appears to have facilitated the proportion of patients with pancreatic malignancies at HSN receiving an HPB surgical consultation. Patients received complex surgeries, closer to their home regions. It is anticipated that these changes may affect overall outcomes and patient satisfaction and will be the focus of future investigations.

Contexte : La concentration des services spécialisés dans les centres urbains pose un défi pour les patients des communautés rurales. Le programme de chirurgie hépatopancréatobiliaire (HPB) d'Horizon Santé-Nord (HSN) est le $10^{\mathrm{e}}$ et plus récent centre HPB d'Action Cancer Ontario; il offre une occasion unique d'évaluer les obstacles à la prestation des soins oncologiques HPB aux patients du Nord de l'Ontario.

Méthodes : Nous avons passé en revue de manière rétrospective les cas adressés au Centre de cancérologie du Nord-Est de l'Ontario et à HSN pour un diagnostic de cancer du pancréas entre 2009 et 2015. Le programme chirurgical HPB a été lancé en juillet 2013. Notre principal paramètre était le délai d'obtention d'une consultation pour une chirurgie HPB. Les paramètres secondaires incluaient la distance à parcourir et le délai d'obtention d'une intervention à visée curative.

Résultats : Notre population comportait 207 patients (98 pré-HPB c. 109 postHPB). Le délai médian d'obtention de la consultation en chirurgie HPB a diminué dans le groupe post-HPB (43 j c. 11 j, $p<0,001)$. Une proportion plus grande de patients atteints de cancer du pancréas dans le groupe post-HPB a obtenu une consultation pour chirurgie HPB ( $34 \%$ c. $74 \%, p<0,001)$, et une diminution de la distance médiane à parcourir pour se rendre à la consultation a été constatée $(411 \mathrm{~km} \mathrm{c.} 79 \mathrm{~km}$, $p<0,001)$. Le délai d'obtention de la chirurgie à visée curative ou de la consultation en oncologie médicale n'a pas augmenté significativement.

Conclusion : Le nouveau programme HPB semble avoir permis d'accroître la proportion de patients atteints de cancer du pancréas ayant pu bénéficier d'une consultation pour chirurgie HPB. Les patients ont pu subir des chirurgies complexes plus près de chez eux. On prévoit que ces modifications auront une incidence sur les paramètres globaux et la satisfaction des patients et qu'elles feront l'objet d'études. 
entralization of specialist services to regionalized centres presents a challenge to patients living in rural communities in Canada. Only $4 \%$ of specialists practise in rural Canada, where up to $20 \%-30 \%$ of Canadians live. ${ }^{1-3}$ Health outcomes in the rural population are generally worse than those in urban centres. ${ }^{3}$ While this is linked to many social determinants of health, access to health care remains an active issue. ${ }^{4}$ With an aging rural population requiring increased health care services, policymakers have struggled to deliver equitable and accessible health care to all Canadians. ${ }^{5,6}$.

Surgical outcomes depend on many factors, including the individual surgeon as well as the systems in which they work. In general, a positive association is noted between higher surgeon and hospital case volumes and outcomes after surgery. ${ }^{7}$ The association between case volume and surgical outcomes is noted in multiple studies involving major cancer surgery, and in particular, pancreatic resection for neoplasms. ${ }^{8-11}$ Better outcomes may additionally be linked to the higher level of expertise and available resources in high-volume centres and the designation of regional centres for pancreatic resection is a logical solution, combining a positive volume-outcome relation with factors such as population, geography and academic capacity. ${ }^{11}$ As a result of these study findings, Cancer Care Ontario developed guidelines with measurements of performance and accountability encouraged through publicly reported quality indicators. ${ }^{12}$ In 2006, Cancer Care Ontario released Hepatic, Pancreatic and Biliary Tract (HPB) Surgical Oncology Standards, highlighting specific criteria pertaining to the surgeon, hospital and system requirements. Included within this guideline was an expected minimum number of HPB surgery cases performed per year. ${ }^{13}$

These standards have led to the designation of regional HPB centres across Ontario. This trend has been documented throughout North America and has resulted in increased centralization of specialist surgical services. ${ }^{12,14}$ Although these HPB programs provide high-quality, complex surgical care, patients must often travel long distances to access these specialized services. Initially, there were 9 HPB programs in Ontario, located in regions of southern Ontario, and it was anticipated that patients from northern Ontario may have challenges in accessing specialist HPB surgery.

The HPB program at Health Sciences North (HSN), located in Sudbury, Ontario, was the tenth and newest HPB centre designated by Cancer Care Ontario. Health Sciences North serves as the location for the Northeast Cancer Centre, and provides intensive care unit services, 24-hour operating rooms, 24-hour diagnostics, therapeutic endoscopy and nutrition services. Sudbury is part of the North East Local Health Integration Network (LHIN), 1 of 14 LHINs in Ontario. The North East LHIN covers an estimated area of $400000 \mathrm{~km}^{2}$ and serves 565000 people. ${ }^{15}$
In this retrospective study, we examined the impact of the development of the HPB surgery program at HSN on the management of pancreatic cancers before and after its inception in July 2013. Time from diagnosis to HPB surgical consultation was the primary study outcome considered. Secondary outcomes included distance travelled for surgical consultation, surgical intervention, time from surgical consultation to operation and time from diagnosis to medical oncology consultation.

\section{Methods}

\section{Data sources and inclusion criteria}

A discharge abstract follows every admission to hospital and day surgery intervention, including endoscopic retrograde cholangiopancreatography (ERCPs), and the information included is coded and collected by the Canadian Institute for Health Information (CIHI) in the Discharge Abstract Database (DAD). ${ }^{16}$ The DAD uses the International Statistical Classification of Disease and Related Problems, 10th revision (ICD-10-CA). Following research ethics board approval, data were retrieved from the Regional Northeastern Cancer Centre and the DAD using codes specific to pancreatic cancer, namely ICD-10-CA code of $\mathrm{C} 25^{\wedge \wedge}$, to generate a list of cases to review of patients at HSN. All patients with pancreatic malignancies had their electronic medical records (EMR) and paper charts abstracted by 3 authors to create a retrospective database during the abstraction period of June 2016 to March 2017.

The study included patients who received a new diagnosis of pancreatic malignancy between January 2009 and December 2015. All pathologies and stages were included. Patients were excluded if the diagnosis was made before the study period, or outside of Ontario. Pancreatic adenocarcinomas were defined through confirming histology and were collected as a subgroup of this population. Atypical or indeterminate cells as well as intraductal papillary mucinous neoplasms (IPMNs), neuroendocrine tumours (NETs) and cystic neoplasms were recorded as a single separate category.

Data collected included consultations with HPB surgical specialists and medical oncologists, and operative management of patients with pancreatic malignancies. The primary outcome was time from diagnosis to any HPB surgical consultation in Ontario. Secondary outcomes included distance travelled for surgical consultation, surgical intervention, time from surgical consultation to operation and time from diagnosis to medical oncology consultation. Consultations included those that occurred in person or by telehealth. Diagnosis was defined as confirmation of a pancreatic mass through a diagnostic imaging technique.

With the HPB program commencing in July 2013, we compared the management of patients 54 months 
pre-HPB program with 30 months post-HPB program. At HSN before July 2013, there were no surgeons with HPB fellowship training. Pancreatic surgery, such as a distal pancreatectomy, was provided with the exception of Whipple procedures. The standard referral process for a Whipple procedure was through an HPB fellowship-trained surgeon in southern Ontario. A single HPB fellowship-trained surgeon joined HSN in July 2013 with an additional HPB fellowship-trained surgeon joining in August 2014. There was no formal mentorship; however, HPB satellite multidisciplinary tumour boards initially occurred in collaboration with Toronto General Hospital.

\section{Statistical analysis}

We divided the 7-year study period into 2 periods based on the inception of the HPB program at HSN in July 2013. We compared the management of pancreatic malignancies in the 54 months pre-HPB program, to 109 pancreatic malignancies in the 30 months of the postHPB program. Statistical significance was calculated using $t$ tests, $\chi^{2}$ tests and Mann-Whitney $U$ tests, as appropriate (2-tailed). We considered results to be significant at $p<0.05$.

\section{Results}

A total of 207 patients (98 pre-HPB v. 109 post-HPB) with a new diagnosis of pancreatic cancer were reviewed from 2009 to 2015, after exclusion of 1 patient, who had received a diagnosis and been seen by an HPB surgeon outside Ontario. Our population included 5 patients in the post-HPB group who were referred to other HPB surgical programs after July 2013. Telehealth or telephone consultations were documented for 2 patients before HPB program inception and were included in our analysis (Table 1).

Pancreatic malignancies, including the subgroup of adenocarcinomas, had shorter median wait times from diagnosis to HPB surgical consultation in the post-HPB group (43 v. $11 \mathrm{~d},[p<0.001]$ for pancreatic malignancies and 48 v. $10 \mathrm{~d},[p<0.001]$ for pancreatic adenocarcinoma) (Table 2). Prior to HPB program implementation, 33 of 98 (34\%) patients with pancreatic malignancies had a consultation with an HPB surgeon compared with 81 of 109 $(74 \%)$ in the post-HPB program group $(p<0.001)$ (Table 3$)$. Median distance travelled to HPB surgery consultation was $411 \mathrm{~km}$ pre-HPB and $79 \mathrm{~km}$ post-HPB $(p<0.001)$ (Table 4).

The median time from HPB surgical consultation to date of curative intent operation for pancreatic malignancies in the pre-HPB group was 18 days compared with 22 days in the post-HPB group ( $p=0.74$ ). In the subgroup of adenocarcinomas, median consultation to curative intent
Table 1. Population demographic and tumour characteristics

\begin{tabular}{|c|c|c|c|}
\hline \multirow[b]{2}{*}{ Characteristic } & \multicolumn{2}{|c|}{ Group; mean \pm SD or no. (\%) } & \multirow[b]{2}{*}{$p$ value } \\
\hline & $\begin{array}{c}\text { Pre-HPB } \\
\text { program } \\
(54 \mathrm{mo}) n=98\end{array}$ & $\begin{array}{c}\text { Post-HPB } \\
\text { program } \\
(30 \mathrm{mo}) n=109\end{array}$ & \\
\hline Age, yr & $71 \pm 12$ & $71 \pm 10$ & 0.60 \\
\hline Male sex & $52(54)$ & $57(52)$ & 0.91 \\
\hline Adenocarcinoma & $49(50)$ & $63(58)$ & \\
\hline $\begin{array}{l}\text { IPMN/NET/cystic } \\
\text { neoplasm }\end{array}$ & $4(4)$ & $11(10)$ & \\
\hline $\begin{array}{l}\text { Distal } \\
\text { cholangiocarcinoma }\end{array}$ & $0(0)$ & $2(2)$ & \\
\hline $\begin{array}{l}\text { No tissue diagnosis/ } \\
\text { indeterminate/ } \\
\text { atypical* }\end{array}$ & $44(45)$ & $32(29)$ & \\
\hline Other (lymphoma) & $1(1)$ & $1(1)$ & \\
\hline \multicolumn{4}{|c|}{$\begin{array}{l}\text { HPB = hepatopancreatobiliary; IPMN = intraductal papillary mucinous neoplasm; } \\
\text { NET = neuroendocrine tumour; } S D=\text { standard deviation. }\end{array}$} \\
\hline
\end{tabular}

Table 2. Time from diagnosis to HPB surgical consultation

(54 mo pre-HPB program and 30 months post-HPB program)

\begin{tabular}{lccc|}
\cline { 1 - 2 } Diagnosis, period & No. patients & Median (IQR), d & $p$ value \\
\hline $\begin{array}{lccl}\text { Pancreatic malignancies } \\
\text { pre-HPB program }\end{array}$ & 19 & $43(28-75)$ & $<0.001$ \\
$\begin{array}{l}\text { Pancreatic malignancies } \\
\text { post-HPB program }\end{array}$ & 71 & $11(5-24)$ & \\
$\begin{array}{l}\text { Adenocarcinomas pre-HPB } \\
\text { program }\end{array}$ & 14 & $48(23-77)$ & $<0.001$ \\
$\begin{array}{l}\text { Adenocarcinomas } \\
\text { post-HPB program }\end{array}$ & 45 & $10(4-23)$ & \\
\cline { 1 - 2 } HPB = hepatopancreatobiliary; IQR = Interquartile range. & \\
\hline
\end{tabular}

Table 3. Interventions of pancreatic malignancies

\begin{tabular}{|c|c|c|c|}
\hline \multirow[b]{2}{*}{ Intervention } & \multicolumn{2}{|c|}{ Group; no. (\%) } & \multirow[b]{2}{*}{$p$ value } \\
\hline & $\begin{array}{c}\text { Pre-HPB } \\
\text { program } \\
(54 \mathrm{mo}) n=98\end{array}$ & $\begin{array}{c}\text { Post-HPB } \\
\text { program } \\
(30 \mathrm{mo}) n=109\end{array}$ & \\
\hline \multicolumn{4}{|l|}{ Pancreatic malignancies } \\
\hline Whipple procedures* & $9(39)$ & $28(53)$ & 0.23 \\
\hline Palliative procedures $\dagger$ & $12(52)$ & $12(23)$ & 0.01 \\
\hline Distal pancreatectomy & 2 (9) & $13(24)$ & 0.11 \\
\hline Curative intent operations & $11(11)$ & $41(38)$ & $<0.001$ \\
\hline $\begin{array}{l}\text { Curative intent operations } \\
\text { adenocarcinomas }\end{array}$ & 9 (9) & $30(28)$ & $<0.001$ \\
\hline $\begin{array}{l}\text { Unresectable due to } \\
\text { metastasis/local invasion }\end{array}$ & $60(61)$ & $45(41)$ & 0.004 \\
\hline $\begin{array}{l}\text { Other reasons for no } \\
\text { operation } \neq\end{array}$ & $15(15)$ & $11(10)$ & 0.26 \\
\hline Total HPB consultations & $33(34)$ & $81(74)$ & $<0.001$ \\
\hline \multirow{2}{*}{\multicolumn{4}{|c|}{$\begin{array}{l}\text { *All } 9 \text { procedures performed pre-HPB program were performed at another centre, } \\
\text { whereas all } 28 \text { performed post-HPB program were performed at Health Sciences North. } \\
\text { TThese include gastrojejunostomy/choledochojejunostomy } \pm \text { venting gastrostomy } \pm \\
\text { jejunostomy feeding tube. These also include attempted but unresectable Whipple } \\
\text { procedures. }\end{array}$}} \\
\hline & & & \\
\hline \multicolumn{4}{|c|}{$\begin{array}{l}\text { †Reasons pre-HPB program were nonoperative candidate due to comorbidities }(n=12) \text {, } \\
\text { patient died }(n=1) \text {, patient declined the surgery offered }(n=3) \text {, and no notes available } \\
(n=2) \text {. Reasons post-HPB program were nonoperative candidate due to comorbidities } \\
(n=7) \text {, patient declined the surgery offered }(n=2) \text {, monitoring of neuroendocinre tumour } \\
\text { and IPMN }(n=2) \text {, and no notes available }(n=1) \text {. }\end{array}$} \\
\hline
\end{tabular}


operation time in the pre-HPB group was 20 days compared with 21 days in the post-HPB group $(p=0.86)$ (Table 5). Median time from diagnosis to medical oncology consultation for the pre- and post-HPB groups did not change (Table 6).

The number of curative intent and palliative operations was determined for the 207 pancreatic malignancy cases reviewed. This was excluding all endoscopic or percutaneous interventions. Curative intent operations increased in the post-HPB program patient population by $19 \%$ in the pancreatic adenocarcinoma group $(p<$ $0.001)$ and $27 \%$ including all pancreatic malignancies $(p<0.001)$. In the pre-HPB group 12 of 23 patients (52\%) underwent palliative operations compared with 12 of 53 patients $(23 \%)$ in the postintervention group $(p=0.01)$ (Table 3). There were no pancreatoduodenectomies (PDs) completed at HSN in the 54 months before July 2013 compared with 28 PDs in the 30 months after the HPB surgery program. Nine PDs were completed in southern Ontario in the pre-HPB group (Table 3). Patients undergoing Whipple procedures in the post-HPB group had a median hospital stay

\begin{tabular}{|c|c|c|c|c|}
\hline Period & $\begin{array}{c}\text { No. } \\
\text { patients }\end{array}$ & $\begin{array}{l}\text { Mean } \pm \text { SD } \\
\mathrm{km}\end{array}$ & $\begin{array}{l}\text { Median (IQR), } \\
\text { km }\end{array}$ & $p$ value \\
\hline Pre-HPB program & 33 & $398 \pm 72$ & 411 (349-447)) & $<0.001$ \\
\hline Post-HPB program & 81 & $148 \pm 176$ & 79 (29-267) & \\
\hline
\end{tabular}

Table 5. Time from diagnosis to date of curative intent operation*

\begin{tabular}{|c|c|c|c|}
\hline Diagnosis, period & No. patients & Median (IQR), d & $p$ value \\
\hline $\begin{array}{l}\text { Pancreatic malignancies } \\
\text { pre-HPB program }\end{array}$ & 9 & $18(15-40)$ & \multirow[t]{2}{*}{0.74} \\
\hline $\begin{array}{l}\text { Pancreatic malignancies } \\
\text { post-HPB program }\end{array}$ & 39 & $22(8-40)$ & \\
\hline $\begin{array}{l}\text { Adenocarcinomas pre-HPB } \\
\text { program }\end{array}$ & 8 & $20(14-44)$ & \multirow[t]{2}{*}{0.86} \\
\hline $\begin{array}{l}\text { Adenocarcinomas } \\
\text { post-HPB program }\end{array}$ & 27 & $21(6-39)$ & \\
\hline \multicolumn{4}{|c|}{$\begin{array}{l}\text { HPB = hepatopancreatobiliary; IQR = interquartile range. } \\
\text { *This includes patients who had curative intent operations for pancreatic malignancies. } \\
\text { Palliative operations are not included. }\end{array}$} \\
\hline
\end{tabular}

Table 6. Time from diagnosis to medical oncology consultation

\begin{tabular}{|c|c|c|c|}
\hline Diagnosis, period & No. patients & Median (IQR), d & $p$ value \\
\hline $\begin{array}{l}\text { Pancreatic malignancies } \\
\text { pre-HPB program }\end{array}$ & 88 & 40.5 (12-76) & 0.59 \\
\hline $\begin{array}{l}\text { Pancreatic malignancies } \\
\text { post-HPB program }\end{array}$ & 63 & 54.0 (19-75) & \\
\hline $\begin{array}{l}\text { Adenocarcinomas pre-HPB } \\
\text { program }\end{array}$ & 50 & 46.5 (14-78) & 0.52 \\
\hline $\begin{array}{l}\text { Adenocarcinomas } \\
\text { post-HPB program }\end{array}$ & 46 & $52.5(15-62)$ & \\
\hline
\end{tabular}

of 10 days, with 2 days of that stay in the intensive care unit. Ninety-day mortality was $0 \%$. There were 6 deaths, with 5 of 6 due to end-stage recurrent/metastatic adenocarcinoma and 1 of 6 due to an unknown cause (patient was lost to follow-up) (Table 7).

\section{Discussion}

The primary outcome of time from diagnosis to HPB surgical consultation was significantly decreased after HPB program inception (Table 2). The overall number of pancreatic malignancies seen at HSN and the Northeast Cancer Centre increased since the inception of the HPB program in July 2013. As well, a significantly larger proportion of patients with pancreatic malignancies received an HPB surgical consultation (Table 3). As the prevalence of pancreatic cancer in northern Ontario is not anticipated to have increased during the study period, these changes likely reflect increased referrals and accessibility to an HPB surgeon. The higher proportion of HPB surgical consultations may reflect a group of patients who previously were not referred or who declined referral to a distant tertiary care centre for HPB surgical consultation and treatment. We acknowledge that the increased proportion of HPB surgical consultations post-HPB program may have been hyperinflated owing to a lack of documentation of informal consultations occurring between the primary care provider and an HPB surgeon before the start of the program.

The secondary outcome of distance travelled for HPB surgical consultation was also significantly decreased after the implementation of the HPB surgery program. While not specifically measured, it is anticipated that travel costs would be reduced, and patient satisfaction likely increased

Table 7. Admission and mortality outcomes among patients who underwent Whipple procedures post-HPB program $(n=27)^{*}$

\begin{tabular}{|c|c|}
\hline Outcome & No. (\%) or median [IOR] \\
\hline Adenocarcinomas & $18(67)$ \\
\hline Adjuvant therapy $\dagger$ & $11(61)$ \\
\hline IPMN/NET/cystic neoplasm & $3(11)$ \\
\hline Otherł & $6(22)$ \\
\hline \multicolumn{2}{|l|}{ Length of admission, $d$} \\
\hline ICU stay§ & $2[1.5-2.5]$ \\
\hline Operative admission & $10[7-10]$ \\
\hline 90-day mortality & $0(0)$ \\
\hline Oncologic mortality (days) & $\begin{array}{c}5(24) \\
295[246-399]\end{array}$ \\
\hline $\begin{array}{l}\text { HPB = hepatopancreatobiliary; IC } \\
\text { mucinous neoplasm; IQR = interc } \\
\text { *One case not recorded. } \\
\text { †Two additional patients were off } \\
\text { ‡Adenomyoma of ampulla }(n=1) \\
\text { gastric malignancy }(n=1) \text {, and ch } \\
\text { §Documented as days stayed in t } \\
\text { १Five deaths were from end-stag } \\
1 \text { death was from an unknown ca }\end{array}$ & $\begin{array}{l}\text { it; IPMN = intraductal papillary } \\
\text { neuroendocrine tumour. } \\
\text { and refused. } \\
\text { clerosing pancreatitis }(n=2) \text {, } \\
\text { 1). } \\
\text { floor transfer. } \\
\text { c pancreatic adenocarcinoma; } \\
\text { as lost to follow-up. }\end{array}$ \\
\hline
\end{tabular}


by having their consultation and treatment locally (Table 3). Finlayson and colleagues ${ }^{17}$ reported on patient preferences for location of care and the implications of regionalization. Using the scenario of a potentially resectable pancreatic cancer, the authors determined the additional operative mortality risk that patients would accept in order to undergo surgery at a local hospital rather than travelling to a distant regional hospital. If the operative mortality risk was $3 \%$ at the regional hospital, $45 \%$ of patients were willing to accept twice the operative mortality risk, and $23 \%$ of patients would accept 4 times the risk if they could have their operation performed locally. While some have concluded that these patients did not fully comprehend the consequences, others suggest that we likely underestimate the value of having health care provided closer to home.

There was an increase in the rates and complexity of curative intent surgical intervention for pancreatic malignancies and adenocarcinomas since the implementation of the HPB surgery program at HSN. The difference in surgical interventions may again reflect an increase in the number of patients who were referred or who agreed to an operative intervention locally. As well, patients who were deemed unresectable may not have been referred previously for consultation and evaluation for palliative interventions. The increase in surgical intervention and consultations is likely, also a reflection of HPB surgeons managing the majority of pancreatic malignancies, including those previously assessed by general surgeons without HPB training.

The secondary outcome of time from consultation to operation was not significantly different than before the HPB surgical program implementation in pancreatic malignancies or the subgroup of pancreatic adenocarcinomas. This may be attributable to small sample size, as we were not able to obtain the date of operation for many patients seen before July 2013. Time from decision to operate until operative date would be a more appropriate secondary outcome; however, this information was often not available. Currently, according to Cancer Care Ontario, the HPB surgical program at HSN is leading provincial wait times for HPB cancer surgery with a median of 23 days from the decision to perform surgery to operation. ${ }^{18}$

Time from diagnosis to medical oncology consultation was not significantly changed. The investigators observed that before July 2013, it was often the medical oncologist who directed the care of patients with pancreatic cancer at HSN. With the development of the HPB surgery program, the surgeons are often involved in directing the care of these patients, including organizing additional imaging, biliary decompression and biopsies when indicated, although this was not statistically measured.

Satellite tumour boards with an established HPB program were extremely helpful in the development of the program at HSN. Input from senior mentors and col- leagues remains an important component in the management of challenging clinical cases.

\section{Limitations}

There are limitations to our study. For the purposes of this retrospective review, it was not feasible to capture the entire population of patients referred from external centres in northeastern Ontario to HPB surgery programs before and after July 2013. While the majority of patients were likely assessed by oncology at the North East Cancer Centre, there may be a small proportion of patients who were seen exclusively at other regional cancer centres, declined referral for surgical consultation, or had pathology that would not benefit from chemotherapy or radiation. The DAD did not include patients if they were referred from the emergency department or a family physician's practice to southern Ontario directly. In addition, difficulty in retrieving HPB surgery consultation dates and operation dates before July 2013, resulted in relatively small sample sizes. While outcomes are reported on Whipple procedures, it is difficult to determine significance with a variable population and variable tumour characteristics.

\section{Conclusion}

Access to specialized surgical care by the rural northern Ontario population remains a concern. Patients who require these services are often confronted by an intimidating diagnosis, long travel times and treatment in an unfamiliar environment. We have examined the impact of the first specialist HPB surgery program in the North East LHIN, located in the province of Ontario, Canada, on the management of pancreatic cancers.

The development of an HPB program in the North East LHIN has increased the number of patients receiving an HPB surgical consultation and undergoing surgical treatment for pancreatic malignancies, including significantly shorter times to consultation, and improvement in distance travelled to consultation and surgery. Patients were able to undergo complex pancreatic operations performed by fellowship-trained HPB surgeons, in their home region.

Further investigation is required to assess whether better access and earlier intervention leads to improved $\mathrm{HPB}$ oncologic outcomes in our patient population. However, with improved access to specialist surgical care, it is anticipated these changes have benefited the quality of care and patient satisfaction in the North East LHIN.

Affiliations: From the Division of General Surgery, Department of Surgery, Schulich School of Medicine and Dentistry, Western University (Hartford, Leslie); the Division of Plastic Surgery, Department of Surgery, University of Manitoba (Hartford, Doucet, Ramkumar, Shum, Asai); the Division of General Surgery, Department of Surgery, Health Sciences North, Northern Ontario School of Medicine (Shum, Ramkumar, Asai). 
Funding: Supported by the Northern Ontario Academic Medicine Association (NOAMA) Clinical Innovation Opportunities Fund Award.

Competing interests: None declared.

Contributors: L. Hartford, J. Shum and K. Asai designed the study. L. Hartford, V. Doucet and J. Ramkumar acquired and analyzed the data, which K. Leslie and K. Asai also analyzed. L. Hartford, V. Doucet, J. Ramkumar, K. Leslie and K. Asai wrote the article, which all authors reviewed and approved for publication.

\section{References}

1. Sibley LM, Weiner JP. An evaluation of access to health care services along the rural-urban continuum in Canada. BMC Health Serv Res 2011;11:20

2. Wilson NW, Couper ID, De Vries E, et al. Inequitable distribution of healthcare professionals to rural and remote areas. Rural Remote Health 2009;9. *need to add page numbers

3. Rural Health in Rural Hands - Ministerial Advisory Council on Rural Health. Ottawa (ON): Health Canada; 2002.

4. Nagarajan KV. Rural and remote community health care in Canada: beyond the Kirby Panel Report, the Romanow Report and the federal budget of 2003. Can F Rural Med 2004;9:245.

5. Joseph AE, Cloutier DS. A framework for modeling the consumption of health services by the rural elderly. Soc Sci Med 1990;30:45-52.

6. Regan S, Wong ST. Patient perspectives on primary health care in rural communities: effects of geography on access, continuity and efficiency [Doctoral dissertation]. University of British Columbia; 2010.

7. Birkmeyer JD, Siewers AE, Finlayson EV, et al. Hospital volume and surgical mortality in the United States. N Engl 7 Med 2002;346:1128-37.
8. Lieberman MD, Kilburn H, Lindsey M, et al. Relation of perioperative deaths to hospital volume among patients undergoing pancreatic resection for malignancy. Ann Surg 1995;222:638.

9. Sosa JA, Bowman HM, Gordon TA, et al. Importance of hospital volume in the overall management of pancreatic cancer. Ann Surg 1998;228:429.

10. Birkmeyer JD, Finlayson SR, Tosteson AN, et al. Effect of hospital volume on in-hospital mortality with pancreaticoduodenectomy. Surgery 1999;125:250-6.

11. Simunovic M, To T, Theriault M, et al. Relation between hospital surgical volume and outcome for pancreatic resection for neoplasm in a publicly funded health care system. CMAJ 1999;160:643-8.

12. Langer B. Role of volume outcome data in assuring quality in HPB surgery. HPB 2007;9:330-4.

13. Marcaccio M, Langer B, Rumble B, et al. Hepatic, pancreatic, and biliary tract (HPB) surgical oncology standards. Cancer Care Ontario; 2006.

14. Stitzenberg K, Sigurdson E, Egleston B, et al. Centralization of cancer surgery: implications for patient access to optimal care. 7 Clin Oncol 2009;27:4671-8.

15. About Our LHIN. North East LHIN; 2017. Available: www.nelhin. on.ca/aboutus.aspx (accessed 2017 Dec 16).

16. Discharge Abstract Database Metadata. Canadian Institute for Health Information; 2017. Available: www.cihi.ca/en/discharge-abstract -database-metadata (accessed 2017 Dec 16).

17. Finlayson SR, Birkmeyer JD, Tosteson AN, et al. Patient preferences for location of care: implications for regionalization. Med Care 1999;37:204-9.

18. Ontario wait times. Cancer Care Ontario; 2017. Available: https://archive. cancercare.on.ca/pcs/treatment/orgguidcserv/hpbcentres/(accessed 2017 Dec 16). 